\title{
(2) OPEN ACCESS \\ Transient osteoporosis of the hip in pregnancy: the orthopaedic management of bilateral neck of femur fractures in the third trimester
}

\author{
Esther Victoria Wright, ${ }^{1,2}$ Ali Zain Naqvi, ${ }^{2}$ Shabana Syed ${ }^{3}$ Htwe Zaw $^{2}$
}

\begin{abstract}
${ }^{1}$ Department of Surgery and Cancer, Imperial College London, London, UK ${ }^{2}$ Trauma and Orthopaedics, Hillingdon Hospitals NHS Foundation Trust, Uxbridge, UK ${ }^{3}$ Obstetrics and Gynaecology, Hillingdon Hospitals NHS Foundation Trust, Uxbridge, UK
\end{abstract}

Correspondence to Esther Victoria Wright; Esther.wright19@imperial.ac.uk

Accepted 2 February 2021

Check for updates

(c) BMJ Publishing Group Limited 2021. Re-use permitted under CC BY-NC. No commercial re-use. See rights and permissions. Published by BMJ.

To cite: Wright EV, Naqvi $A Z$ Syed $\mathrm{S}$, et al. BMJ Case Rep 2021;14:e238659. doi:10.1136/bcr-2020238659

\section{SUMMARY}

Transient osteoporosis of the hip (TOH) is a rare cause of pelvic pain in the third trimester of pregnancy and post partum. Although several cases have been reported in literature, its aetiology is poorly understood. The diagnosis is commonly missed in pregnancy, as the presenting symptoms can be vague, and the risks of radiographic imaging deter clinicians from pursuing investigation. In extreme cases, this pathology presents with neck of femur fractures, with no current guidelines on optimal management. We describe the case of a 24-year-old woman who presented with bilateral neck of femur fractures at 34 weeks gestation. Following an emergency caesarean section, operative management consisted of bilateral closed reduction and internal fixation using dynamic hip screws. Postoperative radiographs demonstrated failure of fixation on the left side, which was revised to a complex primary arthroplasty. This case demonstrates both the diagnostic and management challenges associated with $\mathrm{TOH}$.

\section{BACKGROUND}

Transient osteoporosis of the hip (TOH) is an uncommon and poorly understood pathology. Although more prevalent within the male population, it is also reported in the third trimester of pregnancy and is associated with fragility fractures. In 1959, Curtiss and Kincaid reported several cases of $\mathrm{TOH}$, all following a self-limiting prognosis with full recovery post partum.

The proposed incidence of $\mathrm{TOH}$ is likely to be inaccurate, due to the non-specific nature of symptoms and the reluctance of medical practitioners and prospective mothers to proceed with radiographic investigations. ${ }^{2}$ Significant differential diagnoses include avascular necrosis (AVN) of the femoral head, osteomyelitis, metastatic lesions, septic arthritis and femoral neck stress fractures. ${ }^{34}$ Diagnosis using magnetic resonance imaging (MRI) is gold standard and classically shows diffuse bone marrow oedema within the femoral head and neck, with associated joint effusion. ${ }^{56}$ This is visible as a reduction in signal intensity on T1-weighted images and a relative increase within T2-weighted images. Furthermore, the use of MRI enables differentiation between $\mathrm{TOH}$ and $\mathrm{AVN}$, which can present initially in a similar manner.

Typical presentation in pregnancy is of atraumatic acute onset hip pain in the third trimester, which may significantly affect mobility. ${ }^{8} \mathrm{TOH}$ associated with pregnancy may affect both hips, although this is rare ${ }^{89}$ Associated fractures are a serious complication which can occur at any point in the disease process, although the majority have been reported post partum. ${ }^{8}{ }^{10-12}$ Due to the limited numbers of reported cases, and variation in gestation at the point of diagnosis, there is no consensus on optimal management. Despite this, in cases requiring operative intervention, several authors report efforts to preserve the femoral head where possible, irrespective of the fracture pattern. ${ }^{2}{ }^{8}$ Nonetheless, rates of failure are high, and many proceed to arthroplasty, as in our case study. ${ }^{10}{ }^{13}$ Duckworth et al determined a failure rate of $32 \%$ in 122 patients $\leq 60$ years of age undergoing surgical fixation for a displaced intracapsular fracture of the femoral neck. In addition, they determined that malreduction in both anteroposterior and lateral projections were not predictive of failure in this cohort. ${ }^{14}$

We describe the case of bilateral neck of femur fractures occurring in the third trimester of pregnancy, which presented a management challenge from both obstetric and orthopaedic perspectives. To our knowledge, this is the first case report to describe both antepartum diagnosis and immediate management of this complex presentation.

\section{CASE PRESENTATION}

In February 2020, a 24-year-old woman, who was $34+2$ weeks pregnant, presented to the emergency department with bilateral hip pain after feeling her legs 'give way' and falling from the doorway of her home. She described feeling a click in her left hip prior to the fall, followed by severe pain bilaterally on impact with immediate inability to weight bear. She sustained no other injuries and both lower limbs were neurovascularly intact. Obstetric examination revealed no concerning features. She reported having attended maternity triage twice in the preceding month with pelvic pain, which was managed with analgesia. Radiographic imaging was not conducted at that time due to the atraumatic presentation and the perceived risks to the fetus associated with radiation. Evidence suggests that the risk of acute radiation syndrome or developmental complications following a plain radiograph of the pelvis in the third trimester is minimal, however, this is not standard practice and maternal concern is expected. ${ }^{15}$

Her obstetric history included an uncomplicated twin pregnancy in 2015, which were delivered by lower segment caesarean section (LSCS). She had a high body mass index (BMI) (32.8) but was 
otherwise fit and well and did not take regular medications. She did not drink alcohol and was a non-smoker. Her family history included an uncle who was managed operatively for AVN of the femoral head at aged 25 .

\section{INVESTIGATIONS}

Initial radiographic imaging demonstrated bilateral minimally displaced subcapital neck of femur fractures (figure 1). These radiographs were taken at emergency presentation at $34+2$ weeks gestation following the patient's fall.

\section{DIFFERENTIAL DIAGNOSIS}

From the history, it was difficult to establish whether the patient's fall was the cause or consequence of her fractures. Specifically, the potential for pre-existing fractures, which became displaced following the fall, were considered. The possibility of atraumatic fractures widened the range of potential differential diagnoses. As $\mathrm{TOH}$ is a diagnosis of exclusion, AVN of the femoral head, osteomyelitis, metastatic lesions, femoral neck stress fractures and septic arthritis were the most significant pathologies to rule out.

The patient was afebrile on presentation, with no known risk factors for infection. Her inflammatory markers were not markedly elevated, which made both osteomyelitis and septic arthritis unlikely diagnoses. She had no history of current or previous malignancy, making a metastatic lesion improbable. Additionally, full length femur radiographs were unremarkable. Further investigations were complicated by her gestation, therefore computerised tomography (CT) scanning to assess for malignancy was not conducted.

MRI is gold standard in differentiating between AVN and TOH, however, conducting this preoperatively was clinically inappropriate, and contra-indicated postoperatively. When assessed in accordance with Steinberg staging, her plain radiographs had no features suggestive of AVN. ${ }^{16}$ Additionally, as this presentation mirrored others reported in the literature, $\mathrm{TOH}$ was considered to be the most likely underlying pathology. 81012131718

\section{TREATMENT}

The patient underwent an emergency LSCS under general anaesthesia to facilitate concurrent internal fixation of both neck of femur fractures using 4-hole dynamic hip screws (DHS) and bilateral antirotation screws; a management plan generated by

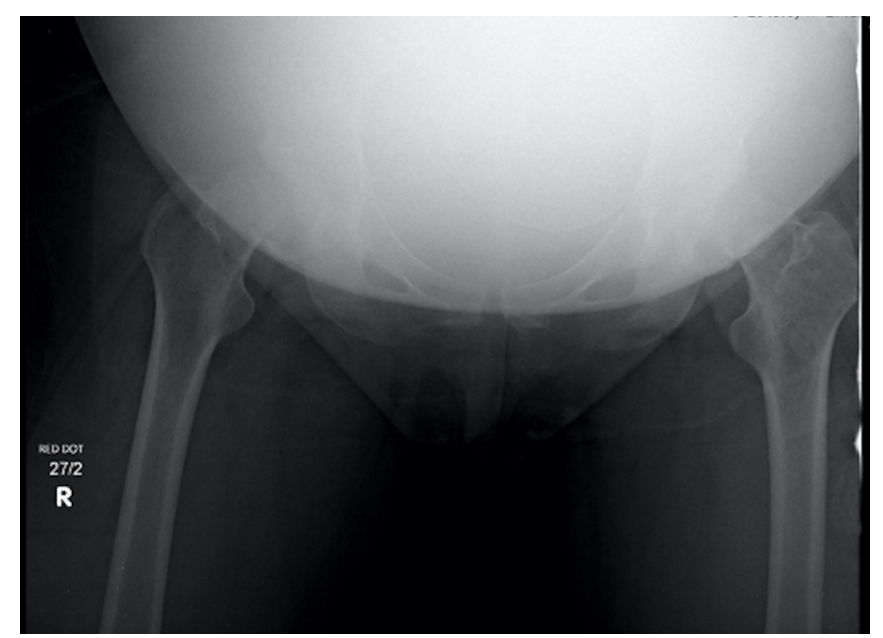

Figure 1 Initial radiographic imaging demonstrated bilateral subcapital neck of femur fractures.

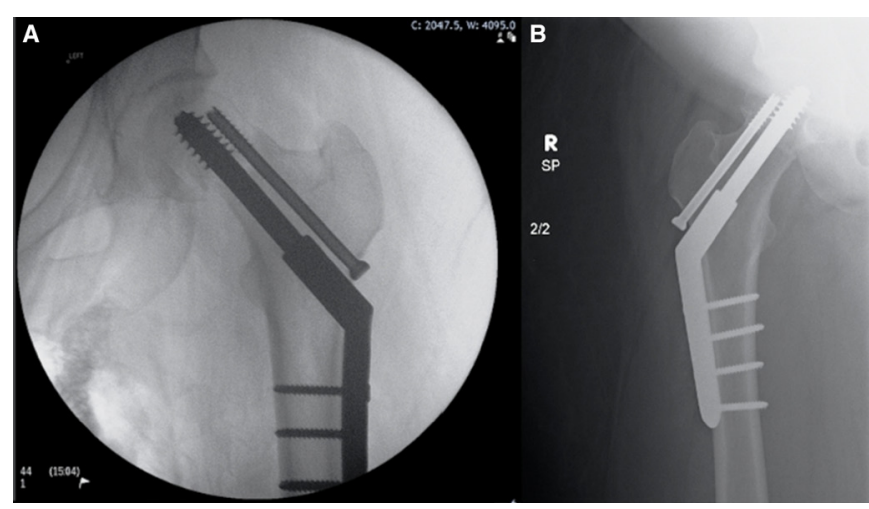

Figure 2 (A) and (B) Intraoperative left proximal femur and postoperative right proximal femur radiographs showing bilateral 4-hole DHS with antirotation screws.

a multidisciplinary team including anaesthetists and obstetricians (figure 2A,B). She was encouraged to fully weight bear postoperatively, both to reduce her risk of venous thromboembolism, and allow her to fulfil childcare needs. Recovery from the LSCS was uncomplicated. Radiographic imaging of the left DHS four days later demonstrated failure, with displacement of the femoral head relative to the screw (figure 3). Consequently, she was advised to remain non-weight bearing on the left side and partially weight bearing on the right. Following an informed decision-making process, she elected to have the left side revised to a complex primary total hip replacement (THR) (Biomet G7 cup, S-ROM stem ceramic on ceramic bearing) (figure 4).

\section{OUTCOME AND FOLLOW-UP}

Six days after her THR, having satisfied the physiotherapists discharge criteria, the patient returned home. At this stage, she was instructed to mobilise with crutches, maintaining partial weight bearing status on the right leg for total of six weeks and full weightbearing on the left THR. Her recovery was complicated only by a superficial wound infection on the left side managed successfully with oral antibiotics.

On resolution of full weight bearing status, she was discharged from regular outpatient physiotherapy. A dual energy X-ray

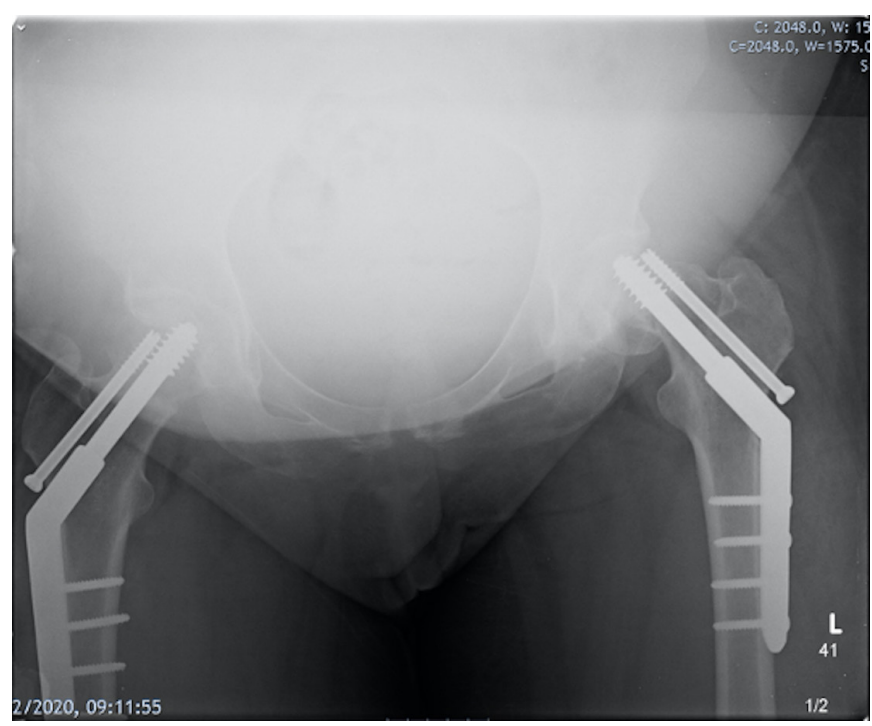

Figure 3 Radiograph taken four days postoperatively demonstrated failure of the left sided DHS. 


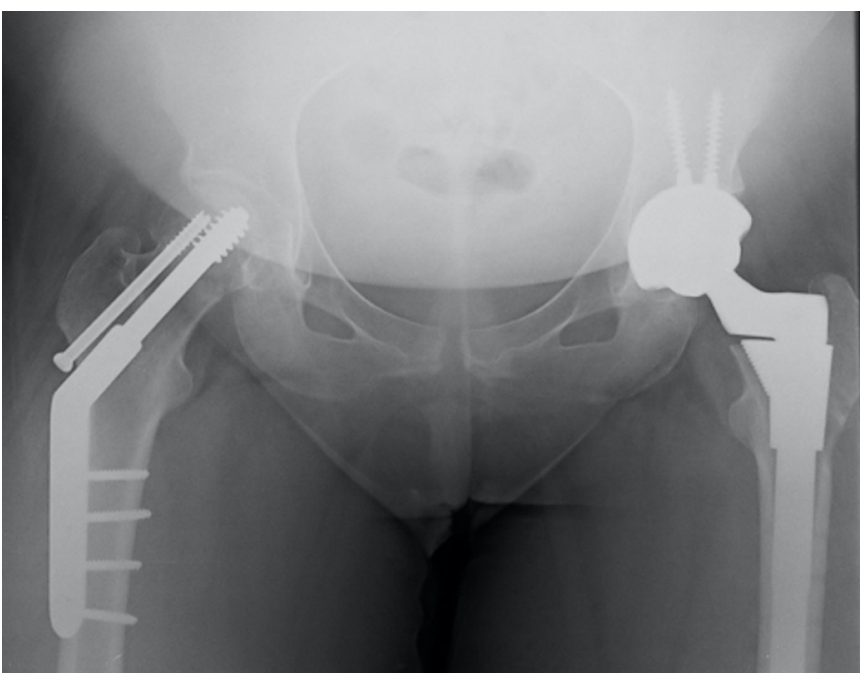

Figure 4 Postoperative radiograph showing revision of the left DHS to a complex primary THR and the right sided 4-hole DHS with antirotation screw in situ.

absorptiometry (DEXA) scan performed two months postoperatively demonstrated adequate bone mineral density (BMD) of the lumbar spine ( $\mathrm{T}$ score $-0.8, \mathrm{Z}$ score -0.7 ). The patient was reviewed in clinic after a further six months and reported excellent progression with full pain free range of motion in both hips. She will be followed up for a minimum period of two years, due to the potential risk of osteonecrosis of the right femoral head.

\section{DISCUSSION}

The incidence of bilateral neck of femur fractures in $\mathrm{TOH}$ of pregnancy is low. Although a handful of cases have been described in literature, to our knowledge only one other reports this pathology diagnosed antenatally. ${ }^{13}$ A recent case control study reported that of 52 patients with confirmed $\mathrm{TOH}$ in pregnancy, $12.1 \%$ presented with a fracture. ${ }^{19}$ The aetiology is unclear. Suggested risk factors include: previous trauma, viral infections, femoral venous stasis caused by pressure from the gravid uterus and complex regional pain syndrome. ${ }^{19}$ Both pelvic and hip pain are frequent complaints in the later stages of pregnancy, therefore rare pathologies such as TOH may be easily misdiagnosed. This hypothesis is supported by our case, as the patient presented twice with pelvic pain, which was dismissed as symphysis pubis dysfunction, prior to sustaining her fractures.

Brodell et al suggested that the benefit of radiographic imaging may outweigh potential risks in the third trimester of pregnancy. ${ }^{20}$ Furthermore, MRI is considered to be low risk at this gestation, and is a sensitive tool to distinguish $\mathrm{TOH}$ from other hip pathologies. ${ }^{21}{ }^{22}$ As such, it should be considered the optimal investigation for persistent hip pain in the later stages of pregnancy and post partum. In this case, MRI was not conducted preoperatively, as safe delivery of the baby became the clinical priority. Fracture fixation was also carried out at this time, to reduce the risk associated with an additional general anaesthetic. Furthermore, within the confines of a District General Hospital that did not have access to 24 hours MRI facilities, delaying definitive intervention to conduct imaging was not in the best interests of mother or baby. Postoperatively, MRI was relatively contra-indicated due to implantation of new metalwork and the limited clinical information likely to be gained after reaming of the femoral neck and head to insert the DHS. ${ }^{6} 1$
Medical management consists of bisphosphonates, alongside calcium and vitamin D replacement therapy, although these were not deficient in our patient. Her calcium level was $2.38 \mathrm{mmol} / \mathrm{L}$ and vitamin D $52 \mathrm{ng} / \mathrm{mL} .{ }^{23}$ Furthermore, the patient's DEXA scan revealed normal BMD two months post partum. These findings are in keeping with the transient disease course and have been replicated in other papers. ${ }^{12} 24$

The choice of optimal surgical intervention to manage displaced subcapital neck of femur fractures in osteoporotic bone is contentious. DHS facilitates union through weight bearing, by allowing movement of the fracture fragments along the implant during axial loading. ${ }^{25}$ Traditionally three parallel cannulated screws had been preferred, although existing evidence, despite being underpowered, suggests fixed angle dynamic constructs such as DHS and rigid constructs such as intramedullary nails are not inferior with regards to rates of non-union. ${ }^{26}$ Based on this evidence, we elected for bilateral DHS with antirotation screws in order to preserve the femoral head and permit immediate weight bearing. Willis-Owen et al report this approach with a successful outcome. ${ }^{8}$ Our main concern remains the long-term risk of osteonecrosis, which has been reported following management with cannulated screws. ${ }^{24}$ Factors thought to contribute to development of osteonecrosis include postoperative weight bearing status, anatomical fracture reduction and time to fracture fixation. $^{27}$ Our management using DHS aimed to reduce these factors by ensuring timely fixation that enabled immediate weight bearing. Several papers report primary management with arthroplasty, although insufficient time has lapsed to evaluate the associated complications in this population. ${ }^{10} 1213$ It is widely accepted that preservation of the femoral head in young patients is preferable, due to their increased functional demands and subsequent requirement for revision. ${ }^{28}$

While our intentions were to avoid arthroplasty, both the intraoperative challenges related to performing bilateral DHS for intracapsular fractures immediately after caesarean section, in addition to the patient's high BMI and potentially reduced bone quality, lead to a suboptimal outcome. There is no isolated reason for failure of the DHS unilaterally. We considered patient factors such as BMD and unequal weight bearing alongside surgical factors such as implant positioning. Furthermore, intraoperative radiographic imaging demonstrated extension of the fracture on the left side into the femoral head, compromising anatomical reduction. Existing cadaveric studies demonstrate that BMD is a better predictor of screw purchase than bone age itself. $^{29}$ Without performing DEXA scanning prior to fracture fixation, the BMD at the time of surgery could not be formally established and can only be assumed to be equal bilaterally. This case therefore demonstrates the complexities of managing this rare presentation, in order to achieve an acceptable balance between early postoperative mobilisation and the risk of procedure failure.

\section{Learning points}

- TOH is a diagnosis of exclusion, which is often missed antenatally.

- Gold standard diagnostic imaging is via MRI, which should be considered a safe modality in the third trimester.

- There is no consensus on optimal management for neck of femur fractures associated with $\mathrm{TOH}$, but effort should be maintained to preserve the femoral head where possible. 
Contributors Both EVW, the corresponding author, and AN were involved in the conception, drafting and final versions of the submitted article. $\mathrm{HZ}$ was involved in revising the article and final approval. SS was involved in conception and final approval.

Funding The authors have not declared a specific grant for this research from any funding agency in the public, commercial or not-for-profit sectors.

Competing interests None declared.

Patient consent for publication Obtained.

Provenance and peer review Not commissioned; externally peer reviewed.

Open access This is an open access article distributed in accordance with the Creative Commons Attribution Non Commercial (CC BY-NC 4.0) license, which permits others to distribute, remix, adapt, build upon this work non-commercially, and license their derivative works on different terms, provided the original work is properly cited and the use is non-commercial. See: http://creativecommons.org/ licenses/by-nc/4.0/.

\section{REFERENCES}

1 Curtiss Jr PH, Kincaid WE. Transitory demineralization of the hip in pregnancy. A report of three cases. J Bone Joint Surg Am 1959;41-A:1327-33.

2 Kasahara K, Kita N, Kawasaki T, et al. Bilateral femoral neck fractures resulting from pregnancy-associated osteoporosis showed bone marrow edema on magnetic resonance imaging. J Obstet Gynaecol Res 2017;43:1067-70.

3 Axt-Fliedner R, Schneider G, Seil R, et al. Transient bilateral osteoporosis of the hip in pregnancy. A case report and review of the literature. Gynecol Obstet Invest 2001;51:138-40.

4 Debnath UK, Kishore R, Black RJ. Isolated acetabular osteoporosis in TOH in pregnancy: a case report. South Med J 2005;98:1146-8.

5 Xyda A, Mountanos I, Natsika M, et al. Postpartum bilateral transient osteoporosis of the hip: MR imaging findings in three cases. Radiol Med 2008;113:689-94.

6 Klontzas ME, Vassalou EE, Zibis AH, et al. Mr imaging of transient osteoporosis of the hip: an update on 155 hip joints. Eur J Radiol 2015;84:431-6.

7 Takatori Y, Kokubo T, Ninomiya S, et al. Transient osteoporosis of the hip. Magnetic resonance imaging. Clin Orthop Relat Res 1991;271:190-4.

8 Willis-Owen CA, Daurka JS, Chen A, et al. Bilateral femoral neck fractures due to transient osteoporosis of pregnancy: a case report. Cases J 2008;1:120.

9 Berman N, Brent H, Chang G, et al. Transient osteoporosis: not just the hip to worry about. Bone Rep 2016:5:308-11.

10 Münker R, Niedhart C, Niethard FU, et al. [Bilateral fracture of the femoral neck following transient osteoporosis in pregnancy]. Z Orthop Ihre Grenzgeb 2007;145:88-90.

11 Emami MJ, Abdollahpour HR, Kazemi AR, et al. Bilateral subcapital femoral neck fractures secondary to transient osteoporosis during pregnancy: a case report. J Orthop Surg 2012;20:260-2.
12 Aynaci O, Kerimoglu S, Ozturk C, et al. Bilateral non-traumatic acetabular and femoral neck fractures due to pregnancy-associated osteoporosis. Arch Orthop Trauma Surg 2008;128:313-6.

13 Wattanawong T, Wajanavisit W, Laohacharoensombat W. Transient osteoporosis with bilateral fracture of the neck of the femur during pregnancy: a case report. J Med Assoc Thai 2001;84 Suppl 2:S516-9.

14 Duckworth AD, Bennet SJ, Keating JF. Fixation of intracapsular fractures of the femoral neck in young patients: risk factors for failure. J Bone Joint Surg Br 2011;93. doi:10.1302/0301-620X.93B6.26432

15 Ratnapalan S, Bentur Y, Koren G. "Doctor, will that X-ray harm my unborn child?". Can Med Assoc J 2008;179:1293-6.

16 Steinberg ME, Hayken GD, Steinberg DR. A quantitative system for staging avascular necrosis. J Bone Joint Surg Br 1995;77:34-41.

17 Yassin A, Jawad I, Coomber R, et al. Non-Traumatic, bilateral subcapital femoral fractures postpartum. BMJ Case Rep 2014;2014:bcr2013201625.

18 Lidder S, Lang KJ, Lee $\mathrm{H}-J$, et al. Bilateral hip fractures associated with transient osteoporosis of pregnancy. J R Army Med Corps 2011;157:176-8.

19 Hadji P, Boekhoff J, Hahn M, et al. Pregnancy-Associated transient osteoporosis of the hip: results of a case-control study. Arch Osteoporos 2017;12:11.

20 Brodell JD, Burns JE, Heiple KG. Transient osteoporosis of the hip of pregnancy. two cases complicated by pathological fracture. J Bone Joint Surg Am 1989;71:1252-7.

21 Guerra JJ, Steinberg ME. Distinguishing transient osteoporosis from avascular necrosis of the hip. J Bone Joint Surg Am 1995;77:616-24.

22 Patenaude Y, Pugash D, Lim K, et al. The use of magnetic resonance imaging in the obstetric patient. J Obstet Gynaecol Can 2014;36:349-55.

23 Emad Y, Ragab Y, El-Shaarawy N, et al. Transient osteoporosis of the hip, complete resolution after treatment with alendronate as observed by MRI description of eight cases and review of the literature. Clin Rheumatol 2012:31:1641-7.

24 Guryel E, Shaikh N, Clark DW. Displaced intracapsular fracture complicating transient osteopoenia of the hip in pregnancy: timing of surgery. Acta Orthop Belg 2010;76:555-8.

25 Lowe JA, Crist BD, Bhandari M, et al. Optimal Treatment of Femoral Neck Fractures According to Patient's Physiologic Age: An Evidence-Based Review. Orthop Clin North Am 2010;41:157-66.

26 Liporace F, Gaines R, Collinge C, et al. Results of internal fixation of Pauwels type-3 vertical femoral neck fractures. J Bone Joint Surg Am 2008;90:1654-9.

27 Ly TV, Swiontkowski MF. Management of femoral neck fractures in young adults. Indian J Orthop 2008:42:3-12.

28 Pauyo T, Drager J, Albers A, et al. Management of femoral neck fractures in the young patient: a critical analysis review. World J Orthop 2014:5:204-17.

29 Hedström M. Are patients with a nonunion after a femoral neck fracture more osteoporotic than others? BMD measurement before the choice of treatment?: a pilot study of hip BMD and biochemical bone markers in patients with femoral neck fractures. Acta Orthop Scand 2004;75:50-2.

Copyright 2021 BMJ Publishing Group. All rights reserved. For permission to reuse any of this content visit https://www.bmj.com/company/products-services/rights-and-licensing/permissions/ BMJ Case Report Fellows may re-use this article for personal use and teaching without any further permission.

Become a Fellow of BMJ Case Reports today and you can:

- Submit as many cases as you like

- Enjoy fast sympathetic peer review and rapid publication of accepted articles

- Access all the published articles

Re-use any of the published material for personal use and teaching without further permission

Customer Service

If you have any further queries about your subscription, please contact our customer services team on +44 (0) 2071111105 or via email at support@bmj.com.

Visit casereports.bmj.com for more articles like this and to become a Fellow 